\title{
Music activities as a meaningful context for teaching elementary students mathematics: a quasi-experiment time series design with random assigned control group
}

\author{
Song A. An ${ }^{1}$, and Daniel A. Tillman² \\ ${ }^{1}$ Department of Teacher Education, University of Texas at El Paso, El Paso, U.S.A. \\ ${ }^{2}$ Department of Teacher Education, University of Texas at El Paso, El Paso, U.S.A. \\ For correspondence: saan@utep.edu
}

\begin{abstract}
:
The purpose of the current research was to examine the effects of a sequence of classroom activities that integrated mathematics content with music elements aimed atproviding teachers an alternative approach for teaching mathematics. Two classes ofthird grade students $(n=56)$ from an elementary school in the west coast of the United States participated in the research. A random assignment pretest-posttest controlgroup design was used to examine students' changes in mathematical ability betweenthe two groups. A quasi-experiment time series design with multiple pretests, midtests and posttests was utilized for investigating the effects of music-mathematics lessonson students' mathematics process ability level. The results demonstrated that theintervention of music-mathematics integrated lessons had statistically significantimprovement on the music group students' mathematical abilities.
\end{abstract}

Keywords: mathematical ability, music-mathematics integrated lessons, elementaryeducation, interdisciplinary mathematics pedagogy

\section{Introduction}

Researchers in recent decades identified numerous drawbacks to using traditional mathematics instructional methods and curriculum when teaching K-12 students. Traditional methods of mathematics instruction may sometimes be ineffective partially because of a lack of connections with students' interests and needs (Cumming, 1994). Because traditional instruction methods have prevented some students from reaching their potential learning capacities in mathematics skills and abilities, the National Council of Teachers of Mathematics (NCTM, 2000) in the Equity Principle explicitly described the need for teachers to develop effective methods for supporting the learning of mathematics for all students regardless of their personal characteristics, backgrounds, or physical challenges. One instructional approach that has shown potential to engage different types of students is the utilization of an interdisciplinary teaching method, which has been shown to allow students to apply mathematics concepts through multiple approaches (Hargreaves et al, 2002). Recent research has reported beneficial results for both typical students and those with intellectual disabilities, with benefits including: (1) promoting communication among students and offering new challenges for higher levels of thinking (Erickson, 2001); (2) supporting students in connecting knowledge and developing their creativity through the situated, socially-constructed, and culturally intervening experiences (Marshall, 2005); (3) facilitating transfer of learning by supporting analysis and interpretation from multiple disciplinary perspectives (Chrysostomou, 2004; Mansilla, 2005); (4) providing students with a positive learning environment engaging them in participatory mathematics activities (Robertson \& Lesser, 2013).

The relationships between music and mathematics can be considered at two different levels: (1) the combination of the two subjects into an interdisciplinary music-mathematics framework, and (2) the overlap between the cognitive psychology and abilities of the individual during musical and 
mathematical experiences. Musical elements such as melody, rhythm, intervals, scales and musical instrument design processes are related to several of the K-12 mathematical content areas such as number operations, geometry, and data analysis (Beer, 1998; Harkleroad, 2006; Fauvel, Flood, \& Wilson, 2006). The natural connections between music and mathematics offer elementary teachers a rich educational resource to develop mathematics lessons based on meaningful connections to music activities. Activities such as music composition and musical instrument design can be used to address different mathematics topics (An, Capraro, \& Tillman, 2013). Several researchers in lab settings have investigated how music or music related events may serve as an external stimulus improving students' mathematical cognition proficiencies (e.g. Rauscher, Shaw, \& Ky, 1993; Ivanov, \& Geake, 2003). Mathematics educators have also investigated ways to associate music with mathematics instruction as a mechanism for improving K-12 students' math achievement and attitude (e.g. An, Ma, \& Capraro, 2011; Carrier et al., 2011; Colwell, 2008; Courey et al., 2012; Costa-Giomi, 2004; Johnson \& Edelson, 2003; Lesser, 2001), and findings from these studies have indicated that music can have a positive impact on students' mathematics achievement and attitudes.

However, these experimental research studies described were conducted in a lab setting with music used in its original unedited format (e.g. Fitzpatrick, 2006; Rauscher et al., 1993). Research examining music-mathematics education in more realistic classroom settings is needed for this interdisciplinary pedagogical approach to be more fully developed and evaluated. With the goal of obtaining empirical evidence on this topic within real-world classroom settings, the current study was undertaken in a quasi-experiment time series design with a random assigned control group to investigate the effects of music-mathematics interdisciplinary lessons on students' mathematics process ability levels. A series of music-themed mathematics lessons provided students an approach to understanding mathematics within the context of music activities. In the music group, students' mathematical abilities were assessed though multiple ability tests and their mathematics achievement was compared with the non-music group students. The two specific research questions in the study were:

(1) After the intervention of music-mathematics integrated curriculum and instruction, did the music group have a statistically significantly higher mathematics content achievement mean score than the non-music group?

(2) Across the intervention of music-mathematics integrated curriculum and instruction, did the students' have statistically significant improvements in their mathematical process ability?

\section{Theoretical Framework}

The theoretical framework for the present study was designed with the intention of synthesizing two components that are both recognized as essential to an understanding of the impact of providing a music activities theme to mathematics education: (1) the first component is the cognitive structures and levels of the students, and (2) the second component is the pedagogical methods utilized by the teachers. At the cognitive level of the students, the Mozart effect theory (Rauscher et al., 1993) has been used to describe the impacts of introducing music into education as a background element to mathematics learning, and the positive impacts upon students' development of mathematical abilities. At the pedagogical level of the teachers, multiple intelligences theory (Gardner, 1983) has been used to explain and explore mathematics pedagogy incorporating musical activities and content as an educational resource. Such music themed activities have been shown to provide students with an emotionally stimulating mathematical learning context, and this in turn functions to reduce their mathematics anxiety (Eisner, 2002; Sylwester, 1995; Upitis \& Smithrim, 2005).

\section{The Impact of Music on Mathematics at the Cognitive Level}

Numerous studies have been conducted that implement experimental research designs investigating how music impacts individuals' mathematical abilities, with some measureable associations having been identified between mathematical cognition proficiencies and music related events including music listening (e.g. Rauscher et al.,1993; Cheek \& Smith, 1999; Hetland, 2000; Ivanov, \& Geake, 2003) and actively learning musical instruments (Bilhartz, Bruhn, \& Olson, 2000; Rauscher, et al., 1997; Rauscher \& Rupan, 2000). A number of possible reasons have been theorized by researchers to explain 
why music or music related practices may improve students' mathematical abilities. One of the key mechanisms that appear relevant is that music stimulates brain activity that is localized in certain areas of the brain that are also responsible for mathematical reasoning (Rauscher et al., 1995). Specifically, Spelke (2008) proposed that the students' experiences of operating melodies, harmonies, and rhythms may activate portions of their brains' systems in a manner that facilitates their ability to learn geometry such as number line construction, and representations of number such as calculation and estimation.

A landmark study, labeled as the "Mozart effect", was published by Rauscher and his colleagues (1993) presented an empirical causal relationship between music listening and spatial-temporal reasoning. In this study, music listening assignments were used as the independent variable for participants, and the spatial-reasoning skills sub-tests from the Stanford-Binet Intelligence Scale were used as the instrument to assess the mathematical abilities. The results demonstrated that participants who were assigned to listen to the Mozart music had significantly higher spatial-reasoning scores than those participants who were assigned into the group listening to relaxing music, or the group listening to silence. A variety of studies were afterwards undertaken to replicate the Mozart effect, with different variations on the theme of investigating how music might impact mathematical abilities. Within these studies, numerous types of music were explored as the treatment intervention, and a number of quantitative and qualitative instruments were used to assess mathematical abilities in areas including the ability to mentally unfold a folded abstract figure (Rauscher et al., 1995; Ivanov \& Geake, 2003; Rideout \& Laubach, 1998), and the ability to solve maze questions (Hui, 2006; Wilson \& Brown, 1997).

As an extension of the research exploring the effects of music listening on mathematical abilities, researchers have also examined the relationships between learning to play a musical instrument and students' mathematical abilities. Results of this research have shown strong positive relationships between participation in learning to play a musical instrument and mathematical abilities (Kafer \& Kennell, 1998). A number of comparison studies have found that students who were involved in musical instruments instruction programs outperformed their peers in mathematics who received no music performance instruction. This same pattern was consistently found in all K-12 grades including preK-K (Costa-Giomi, 1999; Rauscher \& Zupan, 2000), at the elementary school level (Haley, 2001), the middle school level (Whitehead, 2001), and the high school level (Cox \& Stephens, 2006).

\section{The Impact of Music on Mathematics at the Pedagogical Level}

Gardner $(1983,1999)$ proposed the idea of multiple intelligences to re-define and categorize intelligence, and he advocated the existence of a number of distinct intelligences including: linguistic, musical, logical-mathematical, spatial, bodily-kinesthetic, intrapersonal, interpersonal, and naturalistic intelligences. According to the multiple intelligences theory, different students have their unique strengths and weaknesses among these intelligence domains. One of the criticisms of traditional school curricula is that too much attention was focused on linguistic and mathematical intelligence, and the students who were gifted in linguistic or mathematical intelligence domains usually outperformed their peers who are gifted in other intelligence domains (Goodnough, 2001). To solve the unbalanced intelligence developments among learners, educators suggested teachers offer more learning opportunities for students by designing lessons based on students' natural intellectual strengths and personal interests with a goal to prepare activities based on diverse intelligential domains (Armstrong, 2000).

"Equity does not mean that every student should receive identical instruction; instead, it demands that reasonable and appropriate accommodations be made as needed to promote access and attainment for all students" (NCTM, 2000, p. 12). The theory of multiple intelligences provided teachers a conceptual framework to create a variety of instructional resolutions with an overriding goal of fostering students' different individualities to learn mathematics through authentic, active, and student-centered learning experiences (Ball \& Perry, 2009). According to Gardner's theory (1993), musical intelligence is one of the universal domains in all human beings and has rich connections with logical-mathematical intelligence. Music and music related activities can serve as the catalyst to 
develop mathematical abilities, and can be further developed as mathematics activities differentiated to fit students with different learning styles (Selwyn, 1993).Teaching mathematics through music offers opportunities to support students whose most developed intelligence strengths are not necessarily within logical-mathematical domains (Lash, 2004).

An integrated music-math teaching approach can enable students to support knowledge transfer between arts to non-arts content, as they build the connections between empirical musical experiences and abstract mathematical concepts (Catterall, 2005). Patterns, structures, symbols, algebraic and geometric relationships, all these can be explored in both music and mathematics (Fauvel, Flood, \& Wilson, 2006; Loy, 2006). By contextualizing mathematics education into musical composition and instrument design, the natural overlap between these two disciplines offers mathematics educators valuable resources to develop meaningful mathematics activities for students to explore, understand, analyze, and interpret mathematics (An, Capraro, \& Tillman, 2013; An, Ma, \& Cpararo, 2011).A number of recent studies identified empirical evidences that integrated music-mathematics teaching strategies have benefits to students learning mathematics, including: (1) improved motivation to learn math (Glastra, Hake, \& Schedler, 2004), (2) engagement in self-reflection and active inquiry (Parson, 2005); and (3) an enjoyable and collaborative learning environment (Robertson \& Lesser, 2013). Exploring mathematics education in the context of musical composition and instrument design can serve to motivate students to investigate and apply mathematics concepts in authentic ways as they create, analyze, produce and disseminate music (An, Ma, \& Capraro, 2011). Learning mathematics in the context of music activities has allowed students to view the world from an interdisciplinary perspective (Hargreaves \& Moore, 2000). Music themed activities have been shown to be capable of providing students with a learning environment supportive of engaging mathematical knowledge transfer (Johnson \& Edelson, 2003).

\section{Methods}

\section{Participants}

The current study was conducted at an elementary school located in a west coast city in the United States. This school served 699 students in kindergarten through sixth-grade, and functioned on a traditional calendar system. A total of 56 third-grade students with an age range of seven to eight participated in the current study (see table 1). Two classes with 28 students in each were randomly assigned to the two teachers in the school year before the study. Specifically, 28 students ( $n=15$ boys and $n=13$ girls) from class A was randomly assigned in the music group (treatment group). In parallel to the music group, there were 28 student participants from class B ( $n=14$ boys and $n=14$ girls), and these students were randomly assigned in the non-music group (control group). The sample size of two classes was chosen for convenience and logistically having one study class was manageable and the best design for helping the researchers carry out an initial analysis of the intervention.

Table 1.Ethnic demographics information of participants

\begin{tabular}{llllll}
\hline \multirow{2}{*}{ =56 } & \multicolumn{2}{l}{ Ethnic Demographics Information } & English \\
& $\begin{array}{l}\text { African- } \\
\text { American }\end{array}$ & Asia & Caucasian & Hispanic & $\begin{array}{l}\text { Language } \\
\text { Learners }\end{array}$ \\
\hline Music Group & 2 & 19 & 2 & 5 & 14 \\
Non-Music Group & 3 & 18 & 2 & 5 & 12 \\
\hline
\end{tabular}

Prior to the study, the music group teacher attended a series of professional development seminars (total of 10 hours) on music-mathematics integrated instruction. The professional development seminars were led by the authors and college professors. Additionally, the teacher participant had multiple interactions with the authors throughout the intervention period discussing lesson plans and instructional strategies. Prior to the current study, the music group teacher had taught 15 pilot mathematics integrated with music lessons over the previous two years, and received feedback on these lessons from professional development facilitators. The non-music group teacher attended regular professional development programs focused on various topics about effective teaching strategies offered by the school and workshops offered from other professional organizations such as 
California Mathematics Council (CMC) and the National Council of Teachers of Mathematics (NCTM).

\section{Research Design}

For investigations between music group and non-music group, a random assignment pretest-posttest control group design (Shadish, Cook, \& Campbell, 2002) was used to examine students' changes in mathematics content achievement and their dispositions between the two groups (see Figure 1). Before the study, the two classes of students were randomly assigned as the two units to the two teachers. Among the two classes, one class was assigned to the music group teacher to receive musicmathematics integrated lessons; the other class was assigned to the non-music group teacher to receive standard mathematics lessons. As Shadish and his colleagues indicated, the randomized experiment is the utmost preferred design for having a precise and unbiased estimate of the effect of an intervention. The random assignment in the current study equalized the two groups on expectations of all dependent variables before the intervention began, and also reduced any alternative causes that might have confounded the music-mathematics intervention conditions. Before the intervention, a pretest was administered to students in both groups to assess their mathematics content achievement and mathematics disposition. The aim of the pretest was to investigate how the two groups being compared initially differed from each other and to identify whether there was a pretest difference possibly suggesting a selection bias (Shadish et al., 2002).

For investigation within the music group, the student participants were involved in 14 musicmathematics integrated lessons throughout the intervention period. This quasi-experiment time series design employed multiple pretests, mid-tests and posttests (Shadish et al., 2002) for investigating the effects of music-mathematics interdisciplinary lessons on students' mathematics process ability levels (see Figure 1). This design allows researchers to diminish the internal validity threats such as maturation and testing. Specifically, there were 15 tests including: 3 pretests, 3 stage-one midtests, 3 stage-two midtests, 3 stage-three midtests, 3 stage-four midtests, and 3 posttests. The control group was not given these tests throughout the duration of the study the same way the intervention students were primarily due to logistics and a focus on minimizing any interruptions in their classroom.

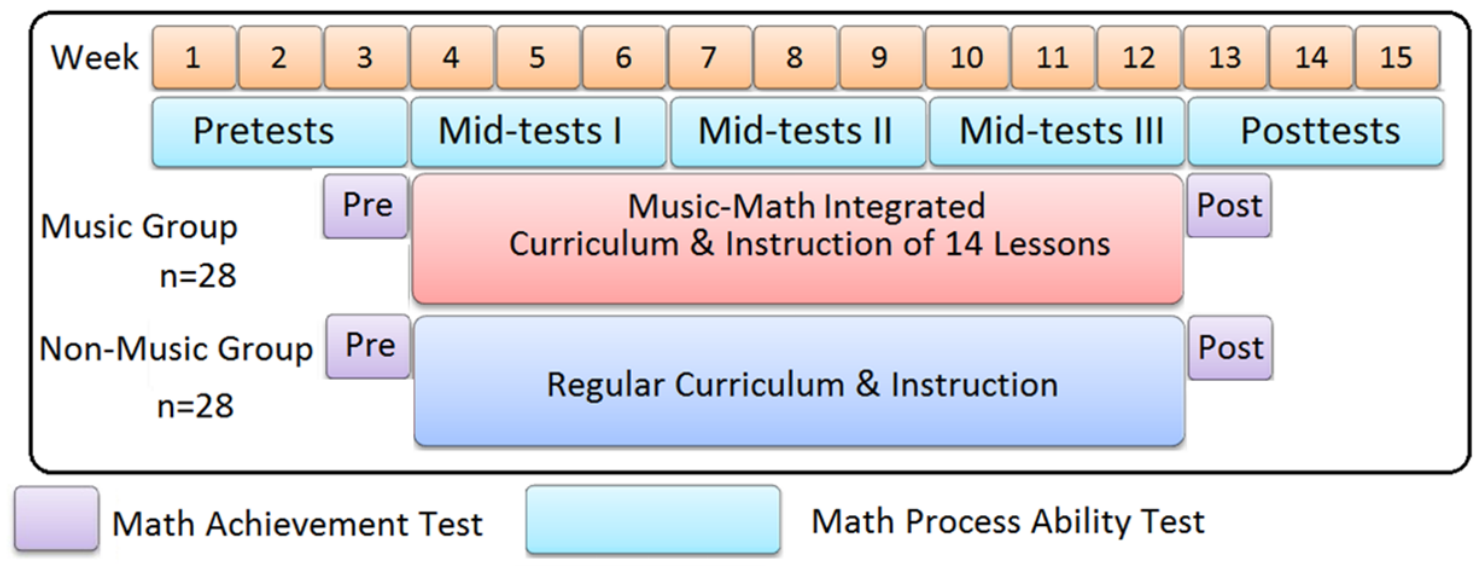

Figure 1.General research design in the current research.

\section{Music Intervention Procedure}

Before the intervention, the teacher who assigned to teach the music group developed 15 musicmathematics integrated lessons during the professional development period a year before the study. An and Capraro's (2011) textbook was used as the main curriculum resource for the teacher participant to develop mathematics lessons. All the lessons were tested and revised by the teacher working with another class of third grade students throughout two semesters. Finally, 14 lessons were selected to be used in the study as the intervention. During the intervention period, each week one or two 45-minute music-mathematics integrated lessons were introduced to the music group students. 
Each music-mathematics integrated activity was focused on one or more major mathematics content areas (see table 2). Music composition and performance were the two primary types of music activities that the teacher participant incorporated into her mathematics lessons. In the music-mathematics integrated lessons, students had opportunities to use graphic notation (e.g., music color cards) and a variety of musical instruments such as handbells, drums, music sticks, and keyboards as physical manipulatives for learning mathematics. Pre-composed musical pieces provided to the students allowed them to apply basic music theories to mathematics learning. Students had opportunities to experiment, practice and apply various mathematics concepts and skills through the series of musicmathematics integrated lessons.

Table 2.Math content focus and music activities in intervention lessons

\begin{tabular}{|c|c|c|c|c|c|c|c|}
\hline \multirow{2}{*}{ Schedule } & Week 1 & Week 2 & Week 3 & \multicolumn{3}{|c|}{ Week 4} & Week 5 \\
\hline & Lesson 1 & Lesson 2 & Lesson 3 & Lesson 4 & Lesson 5 & Lesson 6 & Lesson 7 \\
\hline $\begin{array}{l}\text { Math } \\
\text { Contents }\end{array}$ & Number & Operation & $\begin{array}{l}\text { Data } \\
\text { Analysis }\end{array}$ & Probability & Algebra & $\begin{array}{l}\text { Measure- } \\
\text { ment }\end{array}$ & Algebra \\
\hline $\begin{array}{l}\text { Music } \\
\text { Focus }\end{array}$ & Melody & Singing & Melody & Chords & Intervals & Rhythm & Rhythm \\
\hline \multirow{2}{*}{ Schedule } & Week 5 & Week 6 & Week 7 & & Week 8 & & Week 9 \\
\hline & Lesson 8 & Lesson 9 & Lesson 10 & Lesson 11 & Lesson 12 & Lesson 13 & Lesson 14 \\
\hline $\begin{array}{l}\text { Math } \\
\text { Contents }\end{array}$ & $\begin{array}{l}\text { Data } \\
\text { Analysis }\end{array}$ & Algebra & $\begin{array}{l}\text { Problem } \\
\text { Posing }\end{array}$ & Geometry & Number & Algebra & Geometry \\
\hline $\begin{array}{l}\text { Music } \\
\text { Focus }\end{array}$ & $\begin{array}{l}\text { Music } \\
\text { Form }\end{array}$ & $\begin{array}{l}\text { Music } \\
\text { listening }\end{array}$ & Melody & $\begin{array}{l}\text { Instrumen } \\
\mathrm{t} \\
\text { designing }\end{array}$ & $\begin{array}{l}\text { Handbell } \\
\text { playing }\end{array}$ & Harmony & $\begin{array}{l}\text { Instrument } \\
\text { designing }\end{array}$ \\
\hline
\end{tabular}

The instruction model had five phases for each music-mathematics integrated lesson, with each phase containing varying levels of focus on music and mathematics. In phase one, teachers introduced music knowledge using musical composition theories or musical instruments background, and music was the foci of the instruction. In phase two, teachers introduced the connections between the target music activity and the related mathematical objectives. Both music and mathematics was the focus in phase two, however music retained more of a focus than mathematics. In phase three, teachers facilitated student engagement in the music activities by: (1) directing students to participate in the activity through a correct process, (2) encouraging students to think and asking questions to help students identify the key mathematical ideas from the music experience. Music and mathematics had an equivalent focus in phase three. In phase four, teachers used students' music activity products as a resource to (a) design examples of mathematical concepts and processes, and (b) assign additional mathematics tasks to students based on music activity outcomes. Both music and mathematics were subjects of focus in phase four, but a greater emphasis was placed on mathematics. In phase five, music was not included and teachers focused only on mathematics topics and helping students improve their understanding of mathematical content from unsophisticated to rigorous levels.

\section{Instrument}

Students' mathematics achievement assessments:The mathematics achievement test was designed by the authors, adopted from the California Standard Test (Standardized Testing and Reporting [STAR], 2011), and was used in assessing students' mathematics content achievement between the music group and non-music group students. Two parallel versions of the tests were designed for pretest and the posttest. During the test development process, the test items were sent for review and revision to California school teachers, mathematics teacher supervisors, as well as mathematics education professors in order to strengthen the content validity of the test. Specifically, this mathematics achievement test contained 28 questions items in total with 15 multiple choice questions and 5 open ended questions with multiple sub-questions. This test covered all the five content areas that listed in the Mathematics Content Standards for California Public Schools [MCSCPS] (2009) including: seven items on number sense (NS), five items on algebra and functions (AF), six items on measurement and geometry (MG), three items on statistics, data analysis, and probability (SDAP), and five items on 
mathematical reasoning (MR). Each content area is tested with both multiple choice questions and one open ended question assessing students' mathematics content knowledge from different perspectives. Students' mathematics achievement score were computed by adding the number of items from their correct answers. The overall coefficient alpha reliability of the mathematics achievement test was 0.817 . Specifically, the coefficient alpha reliability of the pretest was 0.801 and of the posttest was 0.832. Sample test items are displayed in Appendix A.

Students' mathematics process assessments: Wu (2008) developed the model-strategy-application (MSA) assessment as a method for determining students' mathematics process ability levels through the inquiry processes. The mathematics process assessment included three components: model, strategy, and application. Specifically, for the assessment of model (M) students were asked to demonstrate their visual approach to solving a problem; for the assessment of strategy (S) students were asked to used mathematical terms and symbols to show the mathematical process to solve the problem; and for the assessment of application (A) students were asked to created their own word problems connecting and applying their learned knowledge to the real world and then solve it. A series of 15 MSA tests were assigned to the student participants in the pretests, midtests, and posttests. For each content area (NS, AF, MG, SDAP, and MR), three tests were developed and assessed. All the test items directly assessed the content that was taught in the lessons based on the music-mathematics activity lessons during the intervention period. Each specific ability area (model-strategy-application) was evaluated independently according to the four-point rubric. The same assessment method was utilized in our pilot study (An et al., 2013), the overall coefficient alpha reliability of the mathematics process ability test was 0.922 , and the sample of mathematics process ability tests as well as the rubrics is contained in Appendix B.

\section{Data Analysis}

For the quantitative analysis of between group assessment, students' pre and post mathematics content achievement test and the mathematics disposition test was analyzed using independent t-tests to determine statistically significant differences in mean scores between the treatment group students and control group students. Specifically, the descriptive information such as means and standard deviations in each comparison was analyzed; moreover the test of significances was analyzed to determine whether there existed any statistically significant differences between pretest and posttest, or between the music group and the non-music group.

For the quantitative analysis of within group assessment, 15 of the music group's mathematics process achievement tests ( 3 pretests, 3 stage-one midtests, 3 stage-two midtests, 3 stage-three midtests, 3 stage-four midtests, and 3 posttests) were analyzed by using repeated measurement ANOVA to determine statistically significant differences in mean scores and standard deviations of the 15 tests among pretest, stage-one midtests, stage-two midtests, stage-three midtests, and posttests throughout the intervention period. Repeated measures ANOVAs were used because the small sample size did not allow for a MANOVA (Stevens, 2002), as the latter analysis has sample size and condition requirements that were not met with the two class design. Post-hoc Scheffe tests were analyzed when significant differences were identified in order to find which means were significantly higher or lower than other means.

Two researchers independently graded for the open-ended problems in the mathematics content achievement test and the mathematics process ability test. The grading results were compared and the inter-rater agreement was $94 \%$. The inconsistencies items in grading were resolved by inviting the third researcher to make final decision. Determining effect sizes enables researchers to assess practical significance concentrating on the how much difference there was between groups as a result of an intervention, or how strong the relationship was among variables. Specifically, Cohen's d was used to compare means between groups on all kinds of t-tests, and the $\eta^{2}$ (correlation ratio) was used to identify the effect sizes in ANOVA (Thompson, 2006). 


\section{Results}

\section{Results for Between Group Assessment}

After correcting the t-tests for the grouping items in each of the five content areas (number sense, algebra and functions, measurement and geometry, statistics/data analysis/probability, and mathematical reasoning), the new adjusted alpha for all tests was changed from the original alpha value on the t-test of 0.05 to the value of 0.0012 in order to reduce the probability of making a type I error (Thompson, 2006). The results (see Table 3) showed that there was no statistically significant differences on the pretests between the music group and non-music group students; whereas on the posttests, the music group students showed statistically significant higher scores in mathematics achievement than non-music group students.

Table 3. The independent and paired t-test results on mathematics achievement

\begin{tabular}{|c|c|c|c|c|c|}
\hline \multirow[t]{2}{*}{$N=56$} & & \multicolumn{2}{|c|}{ Pretest } & \multicolumn{2}{|c|}{ Posttest } \\
\hline & & Music & Non-Music & Music & Non-Music \\
\hline \multirow{2}{*}{$\begin{array}{l}\text { Mathematics } \\
\text { Achievement }\end{array}$} & Mlean & 9.96 & 9.46 & 21.07 & 10.67 \\
\hline & SD & 4.9 & 3.16 & 3.71 & 3.73 \\
\hline \multirow{2}{*}{ Independent t-test } & $p$-value $(t)$ & \multicolumn{2}{|c|}{$0.68(0.453)$} & \multicolumn{2}{|c|}{$<0.001(10.53)$} \\
\hline & Cohen's $d$ & \multicolumn{2}{|c|}{0.12} & \multicolumn{2}{|c|}{3.00} \\
\hline \multirow{2}{*}{$\begin{array}{l}\text { Paired t-test } \\
\text { (Music Group) }\end{array}$} & $p$-value $(t)$ & \multicolumn{4}{|c|}{$<0.001(10.53)$} \\
\hline & Cohen's d & \multicolumn{4}{|c|}{3.38} \\
\hline \multirow{2}{*}{$\begin{array}{l}\text { Paired t-test } \\
\text { (Non-Music Group) }\end{array}$} & $p$-value $(t)$ & \multicolumn{4}{|c|}{$0.031(2.271)$} \\
\hline & Cohen's d & & & & \\
\hline
\end{tabular}

The pretest scores between the music group and non-music group were comparable based on results of the independent $t$-test for mathematics achievement, because no statistically significant differences existed on the pretest. Specifically, the music group students' mean on mathematics achievement pretest was similar to the non-music group students (Mean music $=3.46 \pm 4.90$; Mean non-music $=3.46 \pm$ $3.17)$, and there were no statistically significant differences between the music group and the nonmusic group's mathematics achievement on the pretest $(p=0.68 ; t=0.453)$. The results of the independent t-tests demonstrated that after the intervention of a series of music-mathematics integrated lessons, the music group (Mean music $=21.07 \pm 3.71$ ) had a significantly higher score on mathematics achievement than the non-music group students (Mean non-music $=10.67 \pm 3.73$ ) who did not receive the intervention $(\mathrm{p}<0.001 ; \mathrm{t}=10.53)$. Moreover, large practical significances were found between pretest and posttest within music group and small practical significances were found between pretest and posttest within non-music group, and this was similar to the statistical significance test results between pretest and posttest within music group and within non-music group.

\section{Results For Within Group Assessment}

The results showed that music group students' mathematics process abilities were statistically significantly improved from pretests to posttests. Within the three stages of the middle tests, statistically significant improvement was also identified. In general, the repeated ANOVA results indicated that students' mathematics process ability levels in all three mathematical areas were statistically significantly improved after the intervention (see Table 4) with $\mathrm{p}$ values on all three mathematics process ability areas less than 0.0001. Large effect sizes were found in students' mathematics process ability tests before and after the intervention in all three mathematics process ability areas with $\eta^{2}$ from 0.57 to 0.68 .

In order to assess the changes of mathematics process ability levels, a total of 15 MSA tests were assigned to the student participants. As illustrated in Figure 2, the descriptive statistics analysis demonstrated a noticeable pattern of both improvements of means and reduction of standard 
deviations on all three mathematics process ability levels from pretest to posttest. This finding indicates that not only did most students improve their average mathematics process ability levels throughout the intervention of music-mathematics integrated curriculum and instruction, but also the gap between the high achieving and low achieving students was reduced. The test of significances showed that music group students' overall mathematical abilities were: (a) statistically significantly improved from the pretest to the midtest I; (b) statistically significantly improved from the midtest I to the midtest II; (c) statistically significantly improved from midtest II to midtest III; and (d) stable at a high level from the midtest III to the posttest. Similar improvement patterns were also identified in each of the specific mathematics ability areas (model, strategy and application).

Table 4. The ANOVA of mathematics process ability levels among pretests, midtests and posttests

\begin{tabular}{|c|c|c|c|c|c|c|c|}
\hline \multicolumn{2}{|c|}{$\begin{array}{l}\text { Mathematics Processes } \\
n=28\end{array}$} & Mean & $S D$ & $\begin{array}{l}\mathrm{F} \\
\text { value }\end{array}$ & $\begin{array}{l}p \\
\text { value }\end{array}$ & $\eta^{2}$ & SS \\
\hline \multirow{5}{*}{ Overall } & Pretests & $1.91 \mathrm{a}$ & 0.46 & \multirow{5}{*}{72.73} & \multirow{5}{*}{$<0.001$} & \multirow{5}{*}{0.68} & \multirow{2}{*}{$\begin{array}{l}\text { Between } \\
64.77\end{array}$} \\
\hline & Midtests I & $2.59 b$ & 0.67 & & & & \\
\hline & Midtests II & $3.10 \mathrm{c}$ & 0.50 & & & & \multirow{3}{*}{$\begin{array}{l}\text { Within } \\
30.06\end{array}$} \\
\hline & Midtests III & $3.61 d$ & 0.38 & & & & \\
\hline & Posttests & $3.76 \mathrm{~d}$ & 0.24 & & & & \\
\hline \multirow{5}{*}{ Model } & Pretests & $1.98 \mathrm{a}$ & 0.55 & \multirow{5}{*}{69.08} & \multirow{5}{*}{$<0.001$} & \multirow{5}{*}{0.67} & \multirow{5}{*}{$\begin{array}{l}\text { Between } \\
64.52 \\
\text { Within } \\
31.52\end{array}$} \\
\hline & Midtests I & $2.62 b$ & 0.63 & & & & \\
\hline & Midtests II & $3.10 \mathrm{c}$ & 0.57 & & & & \\
\hline & Midtests III & $3.72 \mathrm{~d}$ & 0.27 & & & & \\
\hline & Posttests & $3.77 \mathrm{~d}$ & 0.27 & & & & \\
\hline \multirow{5}{*}{ Strategy } & Pretests & $1.92 \mathrm{a}$ & 0.56 & \multirow{5}{*}{44.99} & \multirow{5}{*}{$<0.001$} & \multirow{5}{*}{0.57} & \multirow{5}{*}{$\begin{array}{l}\text { Between } \\
67.03 \\
\text { Within } \\
50.27\end{array}$} \\
\hline & Midtests I & $2.26 a$ & 0.84 & & & & \\
\hline & Midtests II & $2.99 \mathrm{~b}$ & 0.60 & & & & \\
\hline & Midtests III & $3.48 \mathrm{c}$ & 0.57 & & & & \\
\hline & Posttests & $3.73 c$ & 0.39 & & & & \\
\hline \multirow{5}{*}{ Application } & Pretests & $1.83 a$ & 0.66 & \multirow{5}{*}{47.24} & \multirow{5}{*}{$<0.001$} & \multirow{5}{*}{0.58} & \multirow{3}{*}{$\begin{array}{l}\text { Between } \\
67.57\end{array}$} \\
\hline & Midtests I & $2.90 \mathrm{~b}$ & 0.77 & & & & \\
\hline & Midtests II & $3.24 b c$ & 0.65 & & & & \\
\hline & Midtests III & $3.63 \mathrm{~cd}$ & 0.47 & & & & \multirow{2}{*}{$\begin{array}{l}\text { Within } \\
48.17\end{array}$} \\
\hline & Posttests & $3.79 \mathrm{~d}$ & 0.31 & & & & \\
\hline
\end{tabular}




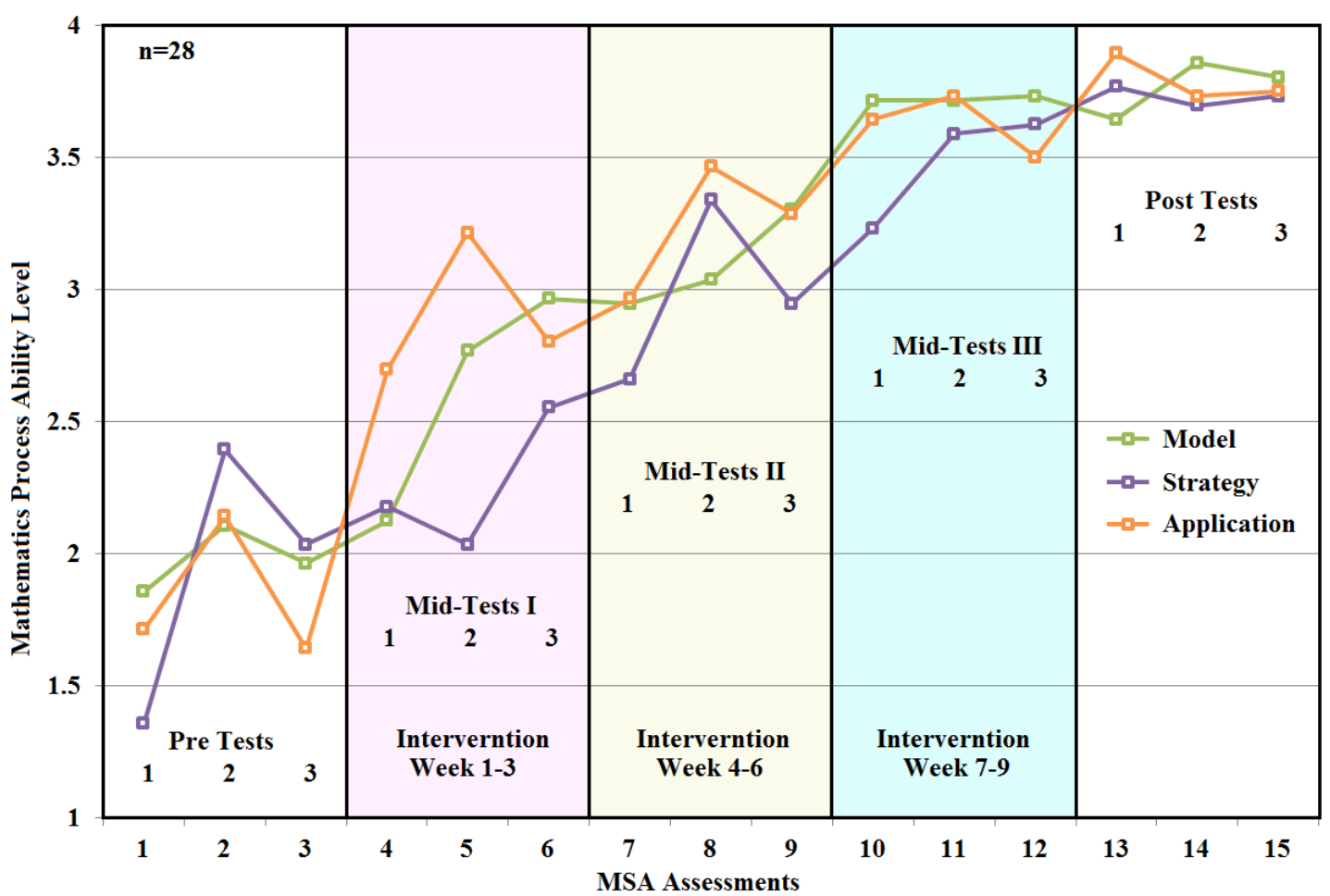

Figure 2.Average ability level of each mathematics process ability test from pretests to posttests.

Specifically, on the 9 sub-tests of the pretest in the three mathematical ability areas, the students showed an average ability level of lower than 2.0. On the midtest I, among the 9 sub-tests on the pretest in the three mathematical ability areas, the students had an average ability level higher than 2.0 including the 6 sub-tests which had levels higher than 2.5. On midtest II, among the 9 sub-tests on the pretest of the three mathematical ability areas, the student participants demonstrated an average ability level of higher than 2.5 including 4 sub-tests which had levels higher than 3.0. On midtest III, among the 9 sub-tests on the pretest of the three mathematical ability areas, the student participants displayed an average ability level of higher than 3.0 including 8 sub-tests which had levels higher than 3.0. On the posttest, among the 9 sub-tests on the pretest of the three mathematical ability areas, the students had an average ability level higher than 3.5 on all the 9 sub-tests' scores higher than 3.5 .

\section{Discussion}

In the current study, music activities were explored as pedagogical resources for providing a context to the design and implementation of mathematics lessons. A series of 14 music-mathematics integrated lessons were designed and implemented by an elementary school teacher as an intervention for the music group students. With the goal of obtaining empirical evidence within realworld classroom settings, the current study was undertaken using a quasi-experimental time series design with a random assigned control group. For the purpose of instrument triangulation, two different but interrelating instruments were used to measure the changes in mathematical abilities for the music group students: one testing for general achievement, and another testing for process ability. The results from both instruments support each other's findings by showing a similar pattern of improvement for the music group students, providing convergent evidence of triangulation. There are multiple interrelated causes for these results, and the next section of this discussion will articulate some of the chief explanations.

The lessons that the teacher taught to the music group students appears to have facilitated their ability to make meaningful connections between and within mathematics content and processes, as well as learning and applying different approaches to solving mathematics problems. In addition to receiving the regular lessons as the non-music group students, the music group students had opportunities to 
have mathematics lessons through a variety of non-routine strategies through active exploration processes and problem-based learning experiences. The music group students were offered numerous mathematics problem solving tasks focused on variety of mathematical concepts. All of the mathematics problems were connected with music, and were individualized based on each student's own music composition works or musical instrument designing. The findings are consistent with previous research on the positive impact of music related activities on students' mathematical ability (Bilhartz, Bruhn, \& Olson, 2000; Courey et al., 2012; Jordan-Decarbo\&Galliford, 2001). In Particular, participation in the music-math integrated activities not only enriched students' view of mathematics problem forms, but also improved their basic mathematics skills by solving problems which might have helped the music group students make significant improvements on mathematical ability (An, Tillman, Boren, \& Wang, 2014). The main reason for the music group students' improvement of mathematical ability is that the students had various opportunities to focus on different mathematical processes and mathematics concepts throughout the intervention lessons.

The overall growth in mathematical ability from the pretests to posttests demonstrated that through music-mathematics interdisciplinary experiences, students had multiple opportunities to improve their abilities with mathematical processes. The significant improvement in students' ability to model mathematics concepts indicates that their capacity to draw pictures, tables, or charts to effectively solve mathematical word problems improved. For example, the graphical notation with different geometrical shapes was used in almost all music mathematics integrated lessons and students experienced multiple ways of representing mathematics content with patterns. Also, in lessons 3, 5, 8 and 9, students had opportunities to make algebraic charts and statistical tables based on different music works. As demonstrated by the significant enhancement of students' ability to strategize at solving mathematics problems, students' skills in using mathematical symbols to show steps for solving mathematics word problems improved. For example, in lessons 1, 2, 5, 6, and 12, students were given various mathematics computation problems related to number sense strengthening their computational strategies. Finally, the significant development of students' ability to apply mathematical information demonstrated that students' ability to create their own word problems by applying mathematical reasoning to the real world was improved. For example, in lessons 5, 7, 9, 13 and 14, students were assigned real world related mathematics problems to learn how to make connections with mathematics and real life scenarios. Additionally, in all lessons, students were encouraged to pose their own problems based on their music works.

The music group students outperformed non-music group students in the mathematical achievement test in the posttest, indicating that the students who received the music-mathematics integrated lessons developed their mathematical abilities at a higher level. We may infer that such development in mathematical abilities is caused by the intervention. The music group students might have improved their understanding of mathematical concepts through exploration and application because the music-mathematic integrated lessons used in the intervention contained music tasks required students to use mathematics knowledge to accomplish tasks (e.g. music composition using algebraic patterns and geometrical transformations), and the mathematics tasks were designed based on students' authentic musical creations (e.g. exploration of the areas of the musical instrument that the students designed). Additionally, during the intervention, students were provided a student-centered learning environment for them to communicate their ideas about the meaning of mathematics concepts, processes and problem solving strategies with their classmates. From these cooperative leaning processes, students were cognitively engaged in participating with the mathematics tasks that the teacher offered in cooperative learning groups (Vygotsky, 1978; Tarım \& Akdeniz, 2008). Moreover, our intervention lessons might have allowed students to manipulate objects, perform activities, and apply the skills that they learned from previous experiences to create new knowledge networks and make sense of new mathematics concepts through interdisciplinary strategies (Chrysostomou, 2004; Mansilla, 2005). These active learning opportunities appear to have allowed students to learn by making mistakes and learning from those mistakes during the arts (e.g., music) to non-arts (e.g., mathematics) knowledge transferring, and this seems to have contributed why the intervention lessons positively affected students' mathematics learning and performance. 
By integrating music connections and representations in mathematics, teachers may have provided effective instruction for students to better understand mathematics from multiple approaches (Gardner, 1993; NCTM, 2000). Teaching specific content areas associated with elements of arts can assist students in developing holistic thinking skills through interdisciplinary connections (Chrysostomou, 2004). Results showed that the music-mathematics integrated lessons positively impacted student gains in mathematical ability throughout the nine-week intervention period. Music composition and playing activities in mathematics instruction enables students to enjoy mathematics and make sense of important mathematical concepts. Due to the emphasis on mathematical processes in the music-mathematics integrated lessons, additional factors may have accounted for this improvement. For example, teaching when using any manipulative effectively or providing activities for students with include multiple representations and connections is crucial for providing students opportunities to create and explore (Clayden et al., 1994).

\section{Conclusion and Educational Implication}

In summary, the students' mathematics achievement improved throughout the music mathematics lesson interventions. During the intervention period the students were taught different mathematics process routes related to a variety of mathematics concepts. As examples: (a) students communicated mathematical ideas with their peers during small group and large group discussions; (b) students represented mathematics concepts with multiple forms including visual, words, symbol, number forms as well as other types of dynamic forms; (c) students connected mathematics content within the mathematics curriculum and with different real life situations; (d) students thought about mathematical meanings from reasonable and logical perspectives; and (e) students solved mathematics problems by using a variety of problem solving strategies. By designing appropriate music activities that were integrated into mathematics lessons, students analyzed, interpreted, and understood mathematics through different disciplinary perspectives. Doing mathematics in the context of music allowed students to present and comprehend mathematics in an engaging way. This study is part of a line of research inquiry (An et al. 2008, 2011, 2013, 2014) that appears to be gaining increasing empirical evidence that mathematics educators should adopt and develop a more comprehensive and connected curriculum, much like the one that John Dewey (1938) argued in favor of over 75 years ago.

Our positive results of elementary students' improvement of mathematical ability suggested that teachers should take advantage of the opportunities that music offers as an authentic and engaging context to help students learn mathematics (An et al., 2013). These positive results, however, might be partially attributable to research limitations. Specifically, due to the small sample size and restriction of students' population's unique demographic structures, the generalization of the results is limited. One of the possible threats to internal validity was the Hawthorne effect. Because the teaching approaches were novel for most students in the music group, some improvement in mathematical abilities might be accounted for in their initial interests about the novel learning experiences. To reduce the Hawthorne effect, 14 music-mathematics lessons were provided to the music group students and thus most students may become familiar with this instructional approach after the first few lessons. In addition, the teacher who was assigned to teach the music group received intensive interdisciplinary pedagogy trainings, and such interdisciplinary pedagogy trainings may not be assessable for other teachers who propose to repeat the study. Moreover, some possible moderating variables could account for the results including different professional development of the two teachers, unbalanced musical dispositions among the two groups of students, and students' maturation throughout the study. However, even with all these limitations, this intervention study provides an opportunity to observe how students' mathematical abilities were developed through learning mathematics integrated with music.

\section{Acknowledgements}

This research is based upon work supported by the National Science Foundation under Grant No. HRD-1342038. Any opinions, findings, and conclusions or recommendations expressed in this 
material are those of the authors and do not necessarily reflect the views of the National Science Foundation.

\section{References}

An, S. A., \& Capraro, M. M. (2011). Music-math integrated activities for elementary and middle school students. Irvine, CA: Education for All.

An, S.A, Capraro, M. M. \&, Tillman, D. (2013). Elementary teachers integrate music activities into regular mathematics lessons: effects on students' mathematical abilities. Journal for Learning through the Arts, 9(1), 1-20.

An, S. A., Kulm, G. O., \& Ma, T. (2008). The effects of a music composition activity on Chinese students' attitudes and beliefs towards mathematics: An exploratory study. Journal of Mathematics Education,1(1), 96-113.

An, S. A., Ma, T., \&Capraro, M. M. (2011). Preservice teachers' beliefs and attitude about teaching and learning mathematics through music: An intervention study. School Science and Mathematics Journal, 111, 236-248.

An, S. A., Tillman, D., Boren, R., \& J. Wang. (2014). Fostering elementary students' mathematics disposition through musicmathematics integrated lessons. International Journal for Mathematics Teaching and Learning, 15(3), 1-18.

Armstrong, T. (2000).Multiple intelligences in the classroom. Arlington, VA: Association for Supervision and Curriculum Development.

Ball, D. \& Perry, C. (2009).An exploration of individual differences in teachers' temperaments and multiple intelligences. Problems of Education in the 21st Century, 18, 21-32.

Beer, M. (1998). How do mathematics and music relate to each other? Brisbane, Queensland, Australia: East Coast College of English.

Bilhartz, T. D., Bruhn, R. A., \& Olson, J. E. (2000).The effect of music training on child cognitive development. Journal of Applied Developmental Psychology, 20, 615-636.

Courey, S. J., Balogh, E., Siker, J. R., \& Paik, J. (2012). Academic music: music instruction to engage third-grade students in learning basic fraction concepts. Educational Studies in Mathematics, 81(2), 251-278.

Carrier, S., Wiebe, E. N., Gray, P., \&Teachout, D. (2011).BioMusic in the Classroom: Interdisciplinary Elementary Science and Music Curriculum Development.School Science and Mathematics, 111(8), 425-434.

Catterall, J. (2005). Conversation and silence: Transfer of learning through the arts. Journal for Learning through the Arts, 1(1), 1-12.

Chrysostomou, S. (2004), Interdisciplinary approaches in the new curriculum in Greece: A focuson music education. Arts Education Policy Review, 105 (5), 23-30.

Clayden, E., Desforges, C., Mills, C., \& Rawson, W. (1994).Authentic activity and learning.British Journal of Educational Studies, 42(2), 163-173.

Colwell, C. M. (2008).Integration of music and core academic objectives in the k-12 curriculum perceptions of music and classroom teachers. Update: applications of research in music education, 26(2), 33-41.

Costa-Giomi, E. (2004). Effects of three years of piano instruction on children's academic achievement, school performance and self-esteem. Psychology of Music, 32(2), 139-152.

Cox, H. A., \& Stephens, L. J. (2006). The effect of music participation on mathematical achievement and overall academic achievement of high school students. International Journal of Mathematical Education in Science and Technology, 37(7), 757763.

Cumming, J. (1994). Educating young adolescents: targets and strategies for the 1990s.Curriculum Perspectives,14(3), 41-44.

Cheek, J. M., \& Smith, L. R. (1999).Music training and mathematics achievement.Adolescence, 34(136), 759-761.

Dewey, J. (1938). Education and experience. Collier Macmillan, New York

Eisner, E. W. (2002). The arts and the creation of mind.Yale University Press.

Erickson, H. L. (2001). Stirring the head, heart, and soul (2nd ed). Thousand Oaks, CA: Corwin Press.

Fauvel, J., Flood, R., Wilson, R., \&Behrends, E. (2006).Music and mathematics.The Mathematical Intelligencer, 28(3), 69-71.

Fitzpatrick, K. R. (2006). The effect of instrumental music participation and socioeconomic status on Ohio fourth-, sixth-, and ninth-grade proficiency test performance. Journal of Research in Music Education, 54(1), 73-84.

Gardner, H. (1983). Frames of mind: The theory of multiple intelligences. New York: Basic Books.

Gardner, H. (1999). Intelligence reframed. New York: Basic Books.

Glastra, F. J., Hake, B. J., \&Schedler, P. E. (2004).Lifelong learning as transitional learning.Adult Education Quarterly, 54(4), 291307.

Goodnough, K. (2001). Multiple intelligences theory: A framework for personalizing science curricula. School Scienceand Mathematics,101(4), 180-193.

Haley, J. A. (2001). The relationship between instrumental music instruction and academic achievement in fourth grade students (Doctoral Dissertation, Pace University). Dissertation Abstracts International, 62(09), 2969A.

Hargreaves, A., and S. Moore. (2000). Curriculum integration and classroom relevance: A study of teachers' practice. Journal of Curriculum and Supervision, 15(2), 89-112.

Hargreaves, A., Earl, L., Moore, S., \& Manning, S. (2002). Learning to change: Teaching beyond subjects and standards. San Francisco, CA: Jossey-Bass.

Harkleroad, L. (2006). The math behind the music. Cambridge, UK: University Press.

Hetland, L. (2000). Learning to make music enhances spatial reasoning. Journal of Aesthetic Education, 34(3/4), 179-238.

Hui, K. (2006). Mozart effect in preschool children?Early Child Development and Care, 176(3-4), 411-419.

Ivanov, V. K., \& Geake, J. G. (2003).The Mozart Effect and primary school children.Psychology of Music, 31(4), 405-413.

Johnson, G.L. \&Edelson, R.J. (2003).Integrating music and mathematics in the elementary classroom. Teaching Children Mathematics, 9 (8), 474-479.

Jordan-DeCarbo, J., \&Galliford, J. (2011). The effect of an age-appropriate music curriculum onmotor and linguistic and nonlinguistic skills of children three to five years of age. In S. L.

Burton \& C. C. Taggart (Eds.), Learning from young children: Research in earlychildhood music (pp. 215-229). Lanham, MD: Rowman\& Littlefield Education.

Kafer, H., \&Kennell, R. (1999).1998 National survey of high school pianists.American Music Teacher, 49, 34-38. 
Lash, M. D. (2004). Multiple intelligences and the search for creative teaching.Paths of Learning, 22, 13-15.

Lesser, L. M. (2001). Musical means: Using songs in teaching statistics. Teaching Statistics, 23(3), 81-85.

Mansilla, V. B. (2005). Assessing student work at disciplinary crossroad.Change: The Magazine of Higher Learning, 37(1), 14-21.

Marshall, J. (2005). Connecting art, learning, and creativity: A case for curriculum integration. Studies in Art Education, 46(3), 227241.

National Council of Teachers of Mathematics.(2000). Principles and standards for school mathematics. Reston, VA: Author.

Peterson, R. (2005). Crossing bridges that connect the arts, cognitive development, and the brain.Journal for Learning through the Arts, 1(2), 13-45.

Rauscher, F. H., Shaw, G. L., \&Ky, K. N. (1993). Music and spatial task performance.Nature, 365, 611.

Rauscher, F. H., Shaw, G. L., \&Ky, K. N. (1995). Listening to Mozart enhances spatial-temporal reasoning: Toward a neuropsychological basis. Neuroscience Letters, 185, 44-47.

Rauscher, F. H., Shaw, G. L., Levine, L. J., Wright, E. L., Dennis, W. R., \& Newcomb, R. L. (1997). Music training causes longterm enhancement of preschool children's spatial-temporal reasoning. Neurological research, 19(1), 2-8.

Rauscher, F. H., \&Zupan, M. A. (2000). Classroom keyboard instruction improves kindergarten children's spatial-temporal performance: A field experiment. Early Childhood Research Quarterly, 15(2), 215-228.

Rideout, B. E., \&Laubach, C. M. (1996). EEG correlates of enhanced spatial performance following exposure to music. Perceptual and Motor Skills, 82, 427-432.

Robertson, W., \& Lesser, L. M. (2013). Scientific skateboarding and mathematical music: Edutainment that actively engages middle school students. European Journal of Science and Mathematics Education, 1(2), 60-68.

Shadish, W. R., T. D. Cook, D. T. Campbell. (2002). Experimental and quasi-experimental designs for generalized causal inference. NY: Houghton Mifflin

Spelke, E. S. (2008). Learning, Arts and the Brain: The Dana Consortium Report on Arts and Cognition. NY/Washington D.C.: Dana Press.

Stevens, J. P. (2002). Applied multivariate statistics for the social sciences, fourth edition.Lawrence Erlbaum Associates. Mahwah, NJ.

Sylwester, R. (1995). An educator's guide to the human brain. Alexandria, VA: Association for Supervision and Curriculum Development.

Tarim, K., \&Akdeniz, F. (2008). The effects of cooperative learning on Turkish elementary students' mathematics achievement and attitude towards mathematics using TAI and STAD methods. Educational Studies in Mathematics, 67(1), 77-91.

Thompson, B. (2006). Foundations of behavioral statistics: An insight-based approach. New York: Guilford.

Upitis, R., \&Smithrim, K. (2005). Learning through the arts: Lessons of engagement. Canadian Journal of Education, 28(1-2), 109-127.

Vygotsky, L. S. (1978). Mind in the society: The development of higherpsychological processes. Cambridge, MA: Harvard University Press.

Wilson, T. L., \& Brown, T. L. (1997).Reexamination of the effect of Mozart's music on spatial-task performance.The Journal of Psychology, 131(4), 365-370

Whitehead, B. J. (2001). The effect of music-intensive intervention on mathematics scores of middle and high school students (Doctoral dissertation, Capella University).

Wu, Z. (2008). Using the MSA Model to Assess Chinese Sixth Graders' Mathematics Proficiency.Journal of Mathematics Education, 1(1), 74-95.

Zafranas, N. (2004). Piano keyboard training and the spatial-temporal development of young children attending kindergarten classes in Greece. Early Child Development and Care, 174(2), 199-211. 


\section{Appendix A}

- Mary had 22 pieces of candy. She gave two pieces each to three of her sisters. How many candies did she have left? ( )
A. 28
B. 26
C. 16
D. 14

- $546 \div 6$ equals what number? ( )
A. 91
B. 90
C. 11
D. 540

- Which two triangles can be put together to form a rectangle?

A.

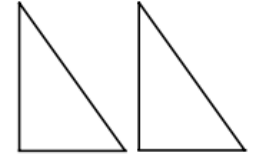

B.

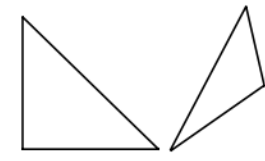

C.

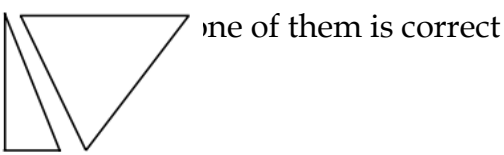

- A bay rias v reu vaus and 1 yellow ball, which term is suitable for describe the chance of get a red ball from the bag?
A. likely
B. certain
C. Unlikely
D. impossible

- Find the answers to the following questions using the graph on the right:

(1) How many more children playing basketball than football? (Show you process)

(2) What is the total number of students who play baseball and basketball? (Show you process)

(3) List at least one more piece of information that you can find from the graph.

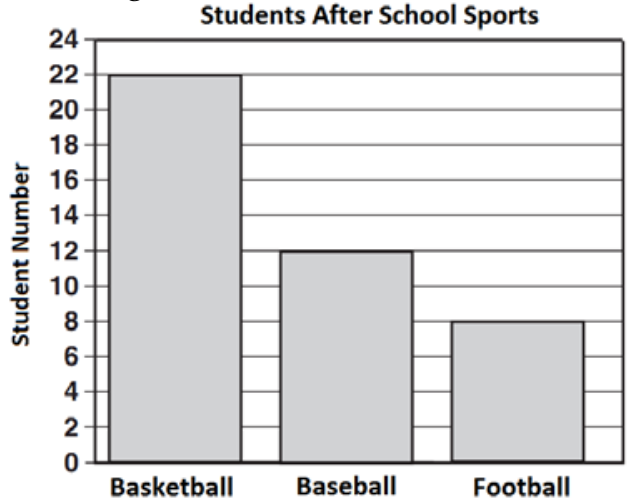




\section{Appendix B}

Mathematics process assessment (5 samples of MSA problems)

\begin{tabular}{|l|l|l|}
\hline $\begin{array}{l}\text { Draw a Picture or Chart to } \\
\text { show your understanding } \\
\text { and solving of the problem }\end{array}$ & $\begin{array}{l}\text { Solve the problem by } \\
\text { showing procedures/steps } \\
\text { or strategies }\end{array}$ & $\begin{array}{l}\text { Create real-world related } \\
\text { word problem for the given } \\
\text { problem above }\end{array}$ \\
\hline & & \\
\hline
\end{tabular}

1. A pie was divided into fifths. Emily ate $1 / 5$ of the pie. Tony ate $2 / 5$ of the pie. Jenny ate $1 / 5$ of the pie. How much of the pie was left?

2. One stamp costs 34 cents. Two stamps cost 68 cents. Three stamps cost $\$ 1.02$. If the cost of each stamp remains the same, how much would 4 stamps cost?

3. Jenny walks her dog $10 \mathrm{~min}$. every day. If she continues this activity for 100 days, what is the total amount of minutes she does this activity for her dog? Draw a function table and find out the function rule to solve the problem.

4. An isosceles triangle must have 2 sides that are the same length. If the perimeter of the isosceles triangle is 20 inches and the length of the 2 equal sides are 14 inches, what is the length of the $3^{\text {rd }}$ side of the isosceles triangle?

5. Miriam put 10 marbles in a paper sack. Six of the marbles were black, three were gray, and one was white. Miriam closed her eyes and took one marble out of the sack. Is it certain, likely, unlikely, or impossible that the marble she picked was white?

\section{MSA Assessment Rubrics for Students' Ability Level of Each Area}

\begin{tabular}{|c|c|c|c|}
\hline Level & Modeling & Strategies & Application \\
\hline $\begin{array}{l}\text { Level } \\
1\end{array}$ & $\begin{array}{l}\text { Either no model or model } \\
\text { completely inappropriate }\end{array}$ & $\begin{array}{l}\text { Either missing computation or } \\
\text { many computational errors }\end{array}$ & $\begin{array}{l}\text { Problem either missing or } \\
\text { impossible to follow }\end{array}$ \\
\hline $\begin{array}{l}\text { Level } \\
2\end{array}$ & $\begin{array}{l}\text { Appropriate model used, but } \\
\text { either not fully demonstrated, } \\
\text { or possibly based on } \\
\text { operation only, did not show } \\
\text { the process of conceptual } \\
\text { developing }\end{array}$ & $\begin{array}{l}\text { Only few computational errors, } \\
\text { but followed rules and } \\
\text { formulas on computations } \\
\text { (routine way), or only by trial } \\
\text { and error }\end{array}$ & $\begin{array}{l}\text { Problem attempted, but } \\
\text { difficult to understand }\end{array}$ \\
\hline $\begin{array}{l}\text { Level } \\
3\end{array}$ & $\begin{array}{l}\text { Appropriate model used, and } \\
\text { the process of modeling } \\
\text { demonstrated }\end{array}$ & $\begin{array}{l}\text { No computational errors, but } \\
\text { solved problem by routine way } \\
\text { or only by trial and error }\end{array}$ & $\begin{array}{l}\text { Problem fairly clear, but } \\
\text { not appropriate or } \\
\text { connected to real life } \\
\text { application }\end{array}$ \\
\hline $\begin{array}{l}\text { Level } \\
4\end{array}$ & $\begin{array}{l}\text { Model used highly efficient } \\
\text { and meaningful, revealing } \\
\text { comprehensive } \\
\text { understanding }\end{array}$ & $\begin{array}{l}\text { No computational errors and } \\
\text { used a flexible or creative } \\
\text { strategy in computation, } \\
\text { revealing complete } \\
\text { understanding of solving }\end{array}$ & $\begin{array}{l}\text { Problem very clear, } \\
\text { appropriate, and } \\
\text { connected to real life } \\
\text { application }\end{array}$ \\
\hline
\end{tabular}

